\title{
O ProJovem Urbano e as juventudes
}

\begin{abstract}
Resumo
Trata-se de um artigo que busca contextualizar quem são os jovens que fizeram parte do Programa Nacional de Inclusão - ProJovem Urbano, com base no entendimento das juventudes. Destacam-se os aspectos mais relevantes ocorridos do programa em Santa Catarina, no período de 2008 a 2012. Objetiva-se trazer para debate as relações vivenciadas nas identidades juvenis, tendo em vista o entendimento e o reconhecimento das diversas juventudes. Inicia-se descrevendo o programa, o público alvo, carga horária, benefícios e o currículo. O ProJovem Urbano é um programa de elevação de escolaridade em nível fundamental, que engloba a qualificação profissional e a participação cidadã, com a finalidade de integrar três dimensões consideradas importantes para todos os sujeitos - educação, trabalho e cidadania. Em um segundo momento do texto, o debate sobre juventudes traz uma relação direta com o cotidiano dos alunos e alunas, a partir dos dados coletados no decorrer do programa. O perfil dos estudantes será descrito e debatido junto com referenciais teóricos que subsidiem uma melhor compreensão dos resultados obtidos.
\end{abstract}

Palavras-chave: Educação de adultos; Jovens; Educação; Juventude.

\author{
Samira de Moraes Maia Vigano \\ Doutoranda em Educação na \\ Universidade Federal de Santa \\ Catarina - UFSC. Professora \\ tutora no Curso de Especialização \\ em Gênero e Diversidade na \\ Escola da UFSC. \\ Brasil \\ samirammvigano@gmail.com
}

\section{Para citar este artigo:}

VIGANO, Samira de Moraes Maia. O ProJovem Urbano e as juventudes. Revista PerCursos. Florianópolis, v. 16, n.31, p. 159 - 184, maio/ago. 2015.

\section{DOI: $\mathbf{1 0 . 5 9 6 5 / 1 9 8 4 7 2 4 6 1 6 3 1 2 0 1 5 1 5 9}$}

http://dx.doi.org/10.5965/1984724616312015159 


\title{
The Urban ProJovem and youths
}

\begin{abstract}
This is an article that seeks to contextualize who are the young people who took part in the National Inclusion Program - Urban ProJovem, based on the understanding of youths. Stands out the most relevant aspects of the program that took place in Santa Catarina, from 2008 to 2012. It aims to bring to debate the lived relations in youth identities in order, understanding and recognition of many youths. Begins describing the program, the target audience, hours, benefits and the curriculum. The Urban ProJovem is an educational lifting program in fundamental level, which includes professional training and citizen participation, in order to integrate three dimensions considered important for all subjects - education, work and citizenship. In a second stage of the text, the debate on youth brings a direct bearing on the daily lives of boys and girls, from the data collected during the program. The profile of students will be described and discussed along with theoretical frameworks that support a better understanding of the results.
\end{abstract}

Keywords: Adult education; Young people; Education; Youth. 


\section{Considerações iniciais}

Ao pensar em criar e recriar ideias, compreender e me reconhecer como produtora e produto em um espaço/tempo, entendendo que meu eu social não está separado do eu profissional, e que toda experiência é válida e nos faz crescer, aprender com o novo, com o diferente, com outras formas de ver e entender o mundo, que contribuíram para as minhas vivências e formações. Sendo assim, as experiências vividas durante 2008 a 2012, período em que atuei no Programa Nacional de Inclusão de Jovens - ProJovem Urbano (PJU), como coordenadora pedagógica, trouxe para minha atuação docente importantes reflexões para melhor compreender as juventudes.

Sempre é bom pensar no lugar de onde se fala, olhar as práticas e percursos seguidos, já que as reflexões se traduzem nas relações vividas, sejam elas sociais e/ou profissionais, sem distinção, todas elas constituem nossa identidade.

É partindo de minhas vivências e de alguns dados coletados durante o período de formação no mestrado em educação que, o presente artigo tem por objetivo discutir e reconhecer os aspectos relacionados aos jovens que fizeram parte do Programa Nacional de Inclusão Social (ProJovem Urbano). Tal escrita é fruto da dissertação de mestrado intitulada "Constituições identitárias no ProJovem Urbano de Santa Catarina: um olhar na docência", que foi apresentada ao Programa de Pós-Graduação em Educação da Universidade Federal de Santa Catarina, em julho de 2014, dentro da linha de pesquisa intitulada: Ensino e Formação de Educadores. O objetivo geral de tal pesquisa foi investigar quem são os professores que atuaram no PJU/SC, na busca de compreender as suas constituições identitárias. Como suporte metodológico utilizei questionários realizados durante a vigência do PJU/SC, cadernos de registros pessoais e da equipe de coordenação e formação, materiais feitos por meio de levantamento de dados realizados pela coordenação nacional do ProJovem Urbano, depoimentos dos participantes, além de um referencial teórico que contribuiu para a descrição e análises dos dados.

Inicio com uma contextualização breve do que é o programa, reconhecendo a importância das políticas públicas de acesso à escolarização, tomando como referência a 
elevação de escolaridade e a formação das identidades juvenis, privilegiando os desdobramentos ocorridos dentro do estado de Santa Catarina.

Os apontamentos, as críticas e os debates, elencados, buscaram suscitar reflexões, provocar transformações, a fim de contribuir com a questão das juventudes; todavia, cabe apresentar inicialmente a proposta do programa, para na sequência, iniciar a discussão sobre a temática sugerida.

\section{O ProJovem Urbano}

O Programa Nacional de Inclusão de Jovens - ProJovem Urbano - faz parte da Política Nacional de Juventude implantada pelo Governo Federal, em 2005, na gestão do Presidente Luiz Inácio Lula da Silva. Prevê o atendimento de jovens que saibam ler e escrever, mas que não possuem o ensino fundamental completo. Muitos desses jovens nunca frequentaram a escola regular, aprenderam a ler na rua, com colegas e vizinhos; outros cursaram até a oitava série, mas por vários motivos não chegaram a concluir o ensino fundamental.

O princípio fundamental desta política de juventude é a integração entre formação básica, qualificação profissional e participação cidadã na busca do reconhecimento do direito de cada um, considerando as especificidades da condição juvenil ${ }^{1}$ e a necessidade de superar a situação de exclusão socioeconômica em que se encontram.

Ao integrar ensino fundamental, qualificação profissional e ação comunitária, o Programa buscou oferecer oportunidade para que os jovens experimentassem novas formas de interação, se apropriassem de novos conhecimentos, re-elaboando suas próprias experiências e sua visão de mundo e, ao mesmo tempo, se re-posicionando quanto a sua inserção social e profissional. (BRASIL, 2008, p. 18)

\footnotetext{
${ }_{1}^{1}$ Para condição juvenil, entende-se como uma etapa do ciclo da vida, de ligação entre uma fase e a outra, caracterizada não mais como um período de preparação para a vida adulta, mas uma etapa marcada por características culturais e históricas (ver Abramo, Kehl, Krauskopf, entre outros).
} 
Por se tratar de um programa de inclusão, o ProJovem proclama a intenção de romper com o ciclo de reprodução de desigualdades, oferecendo aos jovens uma articulação entre educação, cidadania, cultura e formação profissional.

O PJU foi concebido como uma intervenção de caráter emergencial destinada a atender parcela significativa dos jovens com o perfil socioeconômico tipificado como público-alvo, que têm necessidade de retomar a trajetória escolar e prosseguir nos estudos. Assume também caráter experimental ao basear-se em novos paradigmas, constituindo sua proposta curricular a partir de conceitos inovadores que dão suporte à articulação entre o ensino fundamental, a qualificação profissional e a ação comunitária, visando à formação integral do jovem, considerado como protagonista de sua formação. (BRASIL, 2008, p. 18)

Como incentivo para a participação e permanência, os alunos recebem um auxílio financeiro de cem reais por mês, desde que obtenham a frequência mínima de $75 \%$ e façam as atividades didáticas propostas pelo curso.

A carga horária é de 2000 horas, sendo 1440 presenciais e 560 não presenciais, a serem cumpridas ao longo de 18 meses consecutivos. Essa carga horária dividiu-se da seguinte forma: 972 horas de formação Básica (FB - professores das áreas do ensino fundamental, como matemática, português, ciências da natureza, ciências humanas e inglês), 390 horas de qualificação profissional (QP - professores das áreas de formação profissional) e 78 horas de participação cidadã (PC - professores que atuavam com projetos de ação social com os alunos nas comunidades, ministrada por profissionais da área de serviço social, pedagogia ou psicologia).

No ProJovem Urbano é necessário que a qualificação profissional seja articulada com a elevação de escolaridade; essas duas etapas de formação são os pilares para que os alunos do PJU obtenham aprendizagens práticas e sociais que se tornam relevantes para sua vida.

O casamento que parecia indissolúvel entre escola e trabalho está em crise e precisa ser re-pactuado. A concepção moderna de juventude surgida de profundas transformações a partir do século XVIII e 
consolidada após a segunda guerra mundial - tornou a escolaridade uma etapa intrínseca da passagem para a maturidade. Idealmente, o retardamento da entrada dos jovens no mundo do trabalho, garantiria melhor passagem para a vida adulta. Na prática, essa "passagem" não aconteceu em ritmo e modalidades homogêneos nos diferentes países e no interior das juventudes de um mesmo país. Amplos contingentes juvenis de famílias pobres deixaram e deixam a escola para se incorporar prematura e precariamente ao mercado de trabalho informal e/ou experimentar desocupação prolongada. Assim, é urgente re-conectar a escola com o mundo do trabalho. (BRASIL, 2008, p. 29)

No estado de Santa Catarina, o programa ocorreu, pela primeira vez, entre os anos de 2008 até 2012, nos municípios de Araquarí, Balneário Camboriú, Barra Velha, Biguaçu, Camboriú, Criciúma, Içara, Itajaí, Itapema, Lages, Navegantes, Palhoça, São João Batista e São José, sendo executado em 37 unidades escolares da rede estadual ou municipal. 0 programa chegou ao estado, por meio de uma parceria feita entre os governos federal e estadual, através de um termo de adesão que estabelecia as condições e responsabilidades de cada um dos entes federados, de acordo com o Decreto $\mathrm{n}^{\circ}$ $6.628 / 2008$.

O material didático veio diretamente da coordenação nacional, e a formação dos professores e da coordenação local foi realizada pela Fundação Darci Ribeiro, tendo como parâmetro o atendimento dos jovens e os aspectos relacionados à inclusão social.

A coordenação do programa recebia a formação através da coordenação nacional do PJU, sendo 24 horas de formação inicial e 32 horas de formação continuada, para compreender todo o Projeto Político Pedagógico do PJU, a implementação do programa, a finalidade, a atuação com os jovens, as exigências, a carga horária e as leis e diretrizes.

As diretrizes curriculares e metodológicas do ProJovem Urbano são construídas a partir do cruzamento de eixos estruturantes juntamente aos conteúdos curriculares das disciplinas de ciências humanas, língua portuguesa, inglês, matemática, ciências da natureza, qualificação profissional e participação cidadã, por meio de um currículo integrado, que visa atender as 3 dimensões humanas: escolarização, trabalho e cidadania. Os conteúdos trabalhados partem dos seguintes eixos estruturantes: juventude e cultura, 
juventude e cidade, juventude e trabalho, juventude e comunicação, juventude e tecnologia e juventude e cidadania.

\begin{abstract}
Para viabilizar a concepção interdimensional do ProJovem Urbano, é necessário que sua gestão seja inter-setorial e compartilhada pelos órgãos de administração de políticas de juventude, educação, trabalho e desenvolvimento social, em todos os níveis de implementação. Nesse sentido, um aspecto crucial é a criação/implementação/potencialização de instâncias da juventude, tais como secretarias estaduais, municipais e do DF de juventude e conselhos que possam promover a transversalidade da política e dar sustentação às coordenações locais para articular, nesses níveis, as diferentes dimensões do ProJovem Urbano. Os resultados da avaliação do Programa Nacional de Inclusão de Jovens: Educação, Qualificação e Ação Comunitária - ProJovem oferecem indicações no sentido de que, sem desconsiderar a perspectiva intersetorial, a escola seja o lócus obrigatório de funcionamento do ProJovem Urbano. (BRASIL, 2008, p. 27, grifo meu)
\end{abstract}

Com relação às unidades formativas do programa, elas tinham duração de três meses, e funcionavam como orientadoras das temáticas a serem tratadas pelos professores durante o período.

A unidade formativa I: Juventude e Cultura. Nesse sentido, os estudos são relacionados aos jovens e à cultura como construção histórica e coletiva que atribui sentido ao mundo, forma identidades, produz linguagens e ferramentas, institui regras e costumes contribuindo o reconhecimento das diferentes culturas.

A unidade formativa II: Juventude e Cidade. O estudo desta UF gira em torno da juventude e das práticas de ocupação do espaço urbano, a vivência na cidade globalizada, levantando questões relativas às dinâmicas urbanas de inclusão e exclusão social.

A unidade formativa III: Juventude e Trabalho. É uma discussão sobre o mundo do trabalho na sociedade contemporânea, suas transformações, as práticas de inserção dos jovens e a exclusão no trabalho e na escola.

A unidade formativa IV: Juventude e Comunicação. Esta UF tem como objetivo demonstrar como o jovem pode ter acesso à informação e à comunicação. 
A unidade formativa V: Juventude e Tecnologia. É estudada a maneira que a ciência e a tecnologia se apresentam na sociedade contemporânea e suas repercussões na vida do jovem e no acesso às novas tecnologias.

A unidade formativa VI: Juventude e Cidadania. Tem o enfoque sobre as diferenças socioculturais que segmentam a juventude brasileira, tais como: preconceitos e discriminações intra e intergeracionais, desigualdades e diferenças (geração, gênero, raça/etnia, deficiências físico-psíquicas). Nessa unidade, o professor de participação cidadã e o professor orientador (PC e PO) recebem na formação orientações para que ajudem os jovens a sistematizar organicamente os aspectos conceituais através de um levantamento e de um possível engajamento em ações de participação social e cidadã (PLA).

Ao descrever como era articulado o PJU, percebe-se o quanto é preciso reconhecer quem são os jovens que estão nas políticas de elevação de escolaridade, realizando, no decorrer do texto, um debate na compreensão desses sujeitos em processo de inserção, escolarização e profissionalização, expondo características peculiares da juventude.

O olhar para a juventude contribui para a compreensão e construção do espaço escolar, e para o entendimento docente na atuação com os jovens.

\section{As juventudes}

Dentro dos espaços de poder, nas ações governamentais, no que se refere ao que é público, movimentos sociais ${ }^{2}$ e Organizações não Governamentais (ONGs), configuramse ações para atender as juventudes. De acordo com os organismos multilaterais ${ }^{3}$, era necessário agir para conter a juventude, pois havia uma crise pelo excesso de drogas, de violência e falta de educação. O objetivo dessa agenda nacional era de erradicar os

\footnotetext{
${ }^{2}$ A expressão movimentos sociais é muito usada para descrever a participação do cidadão na sua comunidade ou na sociedade em geral.

${ }^{3}$ São organizações internacionais formadas por diversos governos nacionais com a finalidade de promover determinado objetivo comum aos países membros, a exemplo de Onu, Unesco, Unicef, FMI, Bird, Opas e OMS. Fonte: Projeto Terra Azul - http://www.gestaosocial.org.br.
} 
problemas criados pela juventude, "jovens como problema social”. "Vale a pena ressaltar que a expressão os jovens como problema social tem um estatuto diferente da noção de que políticas públicas ocorrem quando jovens deixam de ser estado de coisas para aparecerem como problemas políticos" (CARRANO e SPOSITO, 2003).

A juventude inscreveu-se como questão social no mundo contemporâneo a partir de duas abordagens principais. De um lado, pela via dos "problemas" comumente associados aos jovens - como a delinquência, o comportamento de risco e a drogadição, entre outros -, que demandariam medidas de enfrentamento por parte da sociedade. É sintomático, por exemplo, o fato de que, pari passu à consolidação da afinidade entre a modernização socioeconômica e a configuração da juventude como categoria sociológica específica, firmou-se uma vinculação quase direta entre a temática juvenil e as questões da desordem social, impondo a identificação dos jovens como o grupo prioritário sobre o qual deveriam recair as ações de controle social tutelar e repressivo, promovidas pela sociedade e pelo poder público. De outro lado, a juventude também foi tradicionalmente tematizada como fase transitória para a vida adulta, o que exigiria esforço coletivo principalmente da família e da escola - no sentido de "preparar o jovem" para ser um adulto socialmente ajustado e produtivo. Tendo como referência central o conceito de socialização, esta abordagem sugere que a transição é demarcada por etapas sucessivamente organizadas que garantem a incorporação pelo jovem dos elementos socioculturais que caracterizam os papéis típicos do mundo adulto - trabalhador, chefe de família, pai e mãe, entre outros: à frequência escolar somar-se-ia, em primeiro lugar, a experimentação afetivo-sexual, que seria sucedida progressivamente pela entrada no mercado de trabalho, pela saída da casa dos pais, pela constituição de domicílio próprio, pelo casamento e pela parentalidade. Ao fim deste processo, o jovem-adulto adentraria uma nova fase do ciclo da vida, cuja marca distintiva seria a estabilidade. Sob este enfoque, os "problemas" do comportamento juvenil foram redefinidos, passando a ser compreendidos como desvios ou disfunções do processo de socialização. (AQUINO, 2009, p. 25)

As políticas voltadas à juventude e também às questões que envolvem a Educação de Jovens e Adultos se fortaleceram com os movimentos sociais; muitos questionamentos e inquietações da população sobre as diferenças, sobre os direitos, sobre a formação, começam a eclodir levando o governo a olhar para os jovens e adultos como sujeitos de direito, mesmo que no "Brasil, ainda se observa a ausência de estudos que reconstituam os modos como foram concebidas as ações públicas destinadas aos 
jovens no século XX. Embora, de modo geral, sejam perceptíveis algumas imagens, reiterando algumas das orientações latino-americanas" (CARRANO e SPOSITO, 2003, p. 4).

Nesse aspecto, cabe às políticas de regulação ${ }^{4}$ conter a diversidade, convencendo a população que seguir os modelos é a melhor escolha, e a emancipação traz problemas e os tornam diferentes do que a sociedade deseja, refletindo na criação de ausências tão fortemente percebidas nos enfoques relacionados à Educação de Jovens e Adultos (EJA). As ausências se produzem em várias lógicas: saber, tempo, classe social, poder, produtividade, e culpam os sujeitos pelo seu fracasso, já que não estruturam seus modos de vida e valores dentro da regulação exigida, e por isso ficam excluídos do sistema.

A criação de políticas destinadas a atender a juventude se traduz como um esforço essencial, pois busca identificar alguns pontos de estrangulamento, que por muitos anos não foram trazidos ao debate. A “juventude bem como as questões usualmente associadas à condição juvenil vem orientando, com peso ora mais decisivo, ora menos, as ações direcionadas aos jovens" (AQUINO, 2009, p. 35). Geralmente tais ações se configuram em políticas governamentais pontuais que concentram suas ações nas áreas de educação e trabalho, e acabam por não se estruturarem de fato, como "políticas de juventude, mas como estratégias de atuação da sociedade para orientar a formação de jovens e minimizar seu envolvimento em situações de risco" (AQUINO, 2009, p. 35).

Segundo Miguel Arroyo, "os estudos, as pesquisas e os debates sobre a relação entre educação e desigualdades têm sido um dos campos mais fecundos e instigantes no pensamento educacional progressista e na formulação e gestão, na análise e avaliação de políticas educativas" (ARROYO, 2005, p. 1382). Sendo assim, "as políticas e projetos são pensados como solução, como oportunidades oferecidas; como pontes, ao menos como passarelas ou pinguelas para esses percursos de passagem. Ao estado e suas instituições

\footnotetext{
${ }^{4}$ Regulação refere-se ao papel que o estado tem em demarcar propostas de "modernização" da administração pública e de controle burocrático, por meio de normas e regulamentos rígidos e avaliados por sua eficiência e eficácia. Segundo Tavares (2009), as pessoas que são dominadas e oprimidas pelo estado, não têm a verdadeira consciência, configuram os seus comportamentos a partir das representações dos dominadores por meio da regulação.
} 
cabe oferecer essas pontes e passarelas" (ARROYO, 2005, p. 1390), já que uma ação contínua que enfoque uma verdadeira política pública para a EJA não é realizada.

Utilizei e utilizarei até o final dessa escrita o termo juventudes, no plural, pois tal ação indica respeito às singularidades, e pela diversidade existentes em duas categorias importantes: a categoria de condição juvenil, que é expressa conforme cada sociedade, e cada grupo social lida e representa seus jovens, percebendo ele como um sujeito que, em determinado período da vida, tem transformações psicofísicas e sociais daí advindas das suas relações (FURINI, DURAND e SANTOS, 2011), e a categoria referente à situação juvenil, que diz respeito às trajetórias percorridas pelos jovens:

Por meio de diferentes recortes: de classe, de gênero, de etnia, além de questões regionais, locais e dos grupos culturais os quais estão inseridos. Grupos que fazem parte de suas vivências e que oportunizam ou dificultam a sua constituição e construção do ser jovem. (FURINI, DURAND e SANTOS, 2011, p. 175)

Compreender a pluralidade da juventude é o primeiro passo para poder desvendar quem são os sujeitos que estão nas mais variadas EJAs. Todavia, ao considerar essa pluralidade, torna-se necessário perceber as questões geracionais existentes nesses espaços.

É preciso considerar, contudo, que, se existe um componente geracional que permite definir a juventude pelo que há de específico à sua condição, esta é vivida de forma diversificada e desigual entre os jovens de acordo com suas situações socioeconômicas específicas e com padrões de discriminação e preconceitos vigentes, que repercutem sobre as oportunidades efetivamente disponíveis a cada um (...). Por isso, tornouse usual empregar a expressão juventudes para enfatizar que, a despeito de constituírem um grupo etário que partilha várias experiências comuns, subsiste uma pluralidade de situações que confere diversidade às demandas e necessidades dos jovens. (AQUINO, 2009, p. 31)

Esse diálogo geracional tem relação com a interação vivenciada entre os jovens e os adultos, em um espaço de troca de experiências, como a família, a escola, o mundo do 
trabalho. Toda experiência geracional é inédita e está baseada em saber ouvir e compreender como que cada sujeito se vê e se posiciona no seu próprio tempo. Não há como comparar a juventude de hoje com a de tempos passados; cada momento é associado a sua realidade de mundo, de sociedade, por esse motivo é que

(...) não há somente um tipo de juventude, mas grupos juvenis que constituem um conjunto heterogêneo, com diferentes parcelas de oportunidades, dificuldades, facilidades e poder nas sociedades. Assim, a juventude, por definição, é uma construção social, ou seja, a produção de uma determinada sociedade originada a partir das múltiplas formas como ela vê os jovens, produção esta na qual se conjugam, entre outros fatores, estereótipos, momentos históricos, referências múltiplas, além de diferentes e diversificadas situações de classe, gênero, etnia, grupo etc. Por essa linha, torna-se cada vez mais corriqueiro o emprego do termo juventudes, no plural, no sentido não de se dar conta de todas as especificidades, mas sim de apontar a enorme gama de possibilidades presente nessa categoria. (ABRAMOVAY e ESTEVES, 2008, p. 04)

Há de se considerar também, transições hormonais, inquietações relacionadas à falta de saber a que lugar pertence, ora são considerados "novos" demais para algumas situações, ou "velhos" demais para outras (AQUINO, 2009).

A categoria juventude é nada mais que uma construção social, histórica, cultural e relacional; concebida em uma faixa etária e em etapas de desenvolvimento e amadurecimento que, embora seja uma construção social, possui uma dimensão simbólica, mas reduzi-la apenas a essa dimensão empobrece seu significado e a desmaterializa enquanto sujeitos com identidades próprias (ABRAMOVAY e ESTEVES, 2008).

\section{Os jovens do Pro Jovem Urbano}

Os desafios e resultados diários que envolvem um programa com toda essa dinâmica e abrangência causam uma transformação que possibilita não somente o desenvolvimento dos jovens, mas do próprio professor que se envolve com a proposta, já 
que o envolvimento docente e a aproximação professor/aluno é um dos fatores de permanência dos jovens no programa.

Os jovens atendidos pelo PJU moram em áreas periféricas, são traficantes, prostitutas, mães e pais de família, estão em liberdade assistida, em situação de conflito com a lei, são trabalhadores autônomos ou registrados, são migrantes, religiosos, usuário de drogas, abandonados, marginalizados, mas todos fazem parte dessa diversidade de alunos, caracterizada, muitas vezes, pelo seu "fracasso escolar".

As identidades juvenis podem ser compreendidas a partir de três recortes. O primeiro recorte se refere ao espaço que se desdobra em duas dimensões: o espaço dado e o território como espaço construído. $O$ espaço dado é representado pela cidade que preexiste aos indivíduos. $O$ território, entretanto, é o espaço cotidiano construído pelos atores juvenis. O espaço nesta perspectiva se torna uma extensão do próprio sujeito onde se mesclam a identidade e a memória do grupo. O segundo recorte se relaciona com a alteridade, a necessidade do outro para a constituição do "nós" do grupo. O terceiro recorte se refere à necessidade de a identidade se mostrar para se manter. Os jovens atores urbanos transformam o espaço dado e anônimo da cidade em território onde constroem laços objetiváveis, comemoram-se, celebram-se, inscrevem marcas exteriores em seus corpos que servem para fixar e recordar quem são. (CARRANO, 2007, p. 7-8)

Em relação ao público atendido pelo programa no estado de Santa Catarina, ele será apresentado a partir das pesquisas realizadas nos 14 municípios partícipes do programa, com cerca de 2560 jovens.

Nesse levantamento, verificou-se que a maioria era de mulheres, cerca de $62 \%$, ou seja, mais da metade do público atendido; já em relação a cor/etnia, cerca de $72 \%$ se autodeclararam negros ou pardos; sobre a constituição familiar, aproximadamente $58 \%$ tinham filhos, $84 \%$ moravam na comunidade em que havia o núcleo e $77 \%$ eram responsáveis diretos pelo sustento próprio ou dos demais membros de sua residência.

No campo da educação, por exemplo, constata-se que o número de jovens negros analfabetos, na faixa etária de 15 a 29 anos, é quase duas 
vezes maior que o de jovens brancos. A taxa de frequência líquida (estudantes que frequentam o nível de ensino adequado à sua idade) dos jovens negros é expressivamente menor que a dos jovens brancos, tanto no ensino médio como no superior. Na faixa de 15 a 17 anos, que corresponde ao período em que se espera que o jovem esteja cursando o ensino médio, os brancos apresentam taxa de frequência líquida de $58,7 \%$, contra $39,3 \%$ dos negros. No ensino superior, a desigualdade entre jovens brancos e negros torna-se ainda maior: na faixa etária de 18 a 24 anos, a taxa de frequência líquida para os brancos é de $19,8 \%$, enquanto para os negros é de $6,9 \%$, diferença quase três vezes maior em favor dos jovens brancos. Pode-se lembrar ainda o fato de que os jovens negros estão sobrerrepresentados no segmento de jovens que não trabalham nem estudam, além de sua inserção no mercado de trabalho estar caracterizada por condições de maior precariedade que a dos jovens brancos. (AQUINO, 2009, p. 32)

Não obstante, as questões de gênero demonstram também grande influência na formação das turmas, a exemplo do município de Barra Velha - SC que tinha aproximadamente $80 \%$ de alunas mulheres. A mulher que, culturalmente, teve que assumir a casa e os filhos devido à cultura patriarcal, teve ou tem pouco acesso à escolarização.

As desigualdades entre jovens do sexo masculino e do feminino, de todas as faixas etárias, no que diz respeito à condição de atividade e de estudo refletem, de um lado, a manutenção dos papéis tradicionais de gênero. Cabe aos homens, por mais jovens que sejam, trabalhar para garantir a subsistência da família - daí o fato de procurarem mais cedo o mundo do trabalho ou permanecerem na inatividade (estudando ou não) quando não são chefes de domicílio. Assim, 26,5\% dos jovens de 15 a 17 anos conciliam os estudos com o trabalho e $11,4 \%$ só trabalham, enquanto entre as jovens tais proporções são, respectivamente, de $17 \%$ e $5 \%$. As jovens mulheres, por sua vez, apresentam melhores taxas de frequência escolar líquida, embora ainda tendam a assumir o trabalho doméstico e o cuidado dos filhos quando se casam; com isso, a proporção de jovens mulheres que não estudam nem trabalham é crescente de acordo com a faixa etária, passando de $12 \%$ entre as jovens de 15 a 17 anos a $31,9 \%$ e $32,6 \%$ entre aquelas de 18 a 24 e de 25 a 29 anos, respectivamente. (AQUINO, 2009, p. 34)

As questões pautadas por meio da perspectiva de gênero são relevantes para compreender um pouco mais as juventudes, pois é nas relações de equidade entre 
homens e mulheres, e também, nos aspectos relacionados a questões sociais que são gerados os preconceitos e as discriminações. A mulher se tornou a responsável pelo cuidado da casa e dos filhos, e em razão disso, muitas deixaram seus estudos. Mesmo com o avanço dos movimentos de igualdade de gênero, a mulher ainda encontra dificuldade em afirmar seu espaço.

Segundo Arroyo (2005, p. 22), esses sujeitos são “jovens e adultos com rosto, com histórias, com cor, com trajetórias sócio-étnico-racial, do campo, da periferia”, envolvidos em questões de ordem social, imbricados na etapa da rebeldia, e de moratória social (AQUINO, 2009).

Isso demarca um modo particular de vivência do tempo de juventude que não se identifica com aquilo que o senso comum intui como o modelo do jovem com o direito assegurado de viver a moratória social (Margulis e Urresti, 1996) que the permitiria ser liberado da necessidade do trabalho, dedicar-se à formação, aos estudos, ao associativismo e aos lazeres. A trajetória de busca e inserção no mundo do trabalho dos jovens, especialmente os das famílias mais pobres, é incerta, ou seja, estes ocupam as ofertas de trabalho disponíveis que, precárias e desprotegidas em sua maioria, permitem pouca ou nenhuma possibilidade de iniciar ou progredir numa carreira profissional. A informalidade é crescente à medida que se desce nos estratos de renda e consumo do beneficiário do emprego. (CARRANO, 2007, p. 5)

O relatório do Sistema de Monitoramento e Avaliação (SMA) do ProJovem Urbano disponibilizou alguns dados referentes aos jovens que participaram das atividades do PJU na sua primeira edição, em vários estados do Brasil, que contribuem para reconhecimento das identidades juvenis.

Distribuição por gênero: 53\% dos jovens atendidos no Programa são mulheres.

Faixa de idade: a metade deles tem entre 21 e 22 anos de idade.

Grupo de cor: 70,8\% declararam-se pardos ou negros.

Escolaridade pregressa: $15 \%$ cursaram até a $4^{\text {a }}$ série do ensino fundamental; $53 \%$, até a $5^{\text {a }}$ ou $6^{\text {a }}$; e $33 \%$, até a $7^{\text {a }} ; 10 \%$ não souberam identificar a última série cursada com êxito. Apenas $6 \%$ cursaram 
supletivos ou classe de aceleração, indicando que a grande maioria havia tentado anteriormente concluir o ensino fundamental regular.

Situação familiar: $77,5 \%$ são solteiros, $73 \%$ são chefes de família, $53 \%$ têm filhos.

Trajetória no mundo do trabalho: $20 \%$ nunca trabalharam e 53\% começaram a trabalhar entre 13 e 18 anos de idade; 44\% obtiveram o primeiro trabalho em 2005 ou 2006, sendo que menos de 10\% com vínculo formal; $70 \%$ dos que trabalham não têm carteira assinada e $60 \%$ ficaram menos de seis meses no trabalho, em 2005; mais da metade dos que trabalham nunca fizeram curso profissional e $90 \%$ deles ganham menos que o salário mínimo.

Relações com a comunidade: $84 \%$ moram na comunidade há mais de cinco anos, enquanto $6 \%$ chegaram há menos de dois anos; $46 \%$ convivem com grupos de até cinco amigos; mais de 50\% não participam de qualquer associação; $83 \%$ nunca atuaram como voluntários; $60 \%$ vão à igreja ao menos uma vez por semana.

Relações com o bem público: 98\% possuem título eleitoral e 56\% votariam, mesmo se o voto não fosse obrigatório; $71 \%$ votaram no referendo sobre porte de armas; $87 \%$ não participam de qualquer outro programa federal para educação. (BRASIL, 2008, p. 28-29)

De maneira geral, os dados trazidos pelo SMA do PJU demonstraram que o perfil dos estudantes em várias regiões do Brasil é bem próximo aos dados levantados no estado de Santa Catarina. Um público predominantemente feminino, de cor/etnia parda ou negra, com uma trajetória escolar descontínua, com baixa renda, baixo poder aquisitivo e com oportunidades precárias de inserção no mercado do trabalho.

Para compreender um pouco mais a realidade dos jovens de Santa Catarina e perceber o que os levou à evasão da escola na modalidade regular, foi realizado um breve questionário em três turmas de jovens do programa em SC (Municípios de Barra Velha, Camboriú e Itajaí), resultando nos seguintes dados: dos 80 alunos pesquisados, 38\% abandonaram os estudos para trabalhar, $26 \%$ constituíram uma nova família (gravidez precoce), $20 \%$ explicaram que a família mudou de cidade, $14 \%$ alegaram que a falta de incentivo familiar e/ou a proibição dos companheiros, namorados ou maridos os fez desistir, e apenas $2 \%$ relataram que a distância da escola se constituiu como um agravante para a evasão (Fonte: Arquivo pessoal) ${ }^{5}$.

\footnotetext{
${ }^{5}$ Foram utilizados como fonte, dados do arquivo pessoal que coletei durante a execução do programa no estado de SC.
} 
Na tentativa de superar as mazelas da vida, os jovens vão em busca de um curso de elevação de escolaridade, porém quando algo não corresponde às suas expectativas, a desistência e a evasão acontecem, e por mais que haja um envolvimento com os docentes, os problemas cotidianos e a necessidade de trabalhar se sobrepõem aos estudos.

Como forma de reconhecer alguns olhares dos sujeitos jovens, resgatei certos depoimentos dos alunos e alunas, que foram descritos durante o programa (2008/2012) em Santa Catarina, procurando demonstrar como são visíveis as diferentes trajetórias e expectativas escolares de cada um dos sujeitos. Esses depoimentos foram gravados durante conversas com a equipe da coordenação estadual do programa, e fizeram parte de um estudo sobre o reconhecimento dos sujeitos do PJU em nível nacional. Na intenção de não expor os jovens partícipes do programa, não utilizei seus verdadeiros nomes, direcionei suas identidades para nomes da mitologia grega, de Deuses e Deusas, preservando apenas a letra inicial de seu verdadeiro nome. Os dados pessoais, como idade, estado civil e número de filhos, também dão suporte para o reconhecimento identitário dos sujeitos da EJA, percebendo que, os depoimentos das mulheres, estão direcionados fortemente às relações de gênero socialmente impostas, nas quais, a mulher tem obrigações de cuidado com o lar e com os filhos.

Como pergunta relevante para entender a juventude e a evasão, questionei o porquê de abandonaram a escola. Em geral, as respostas dos alunos denotaram um certo distanciamento entre a linguagem que a escola trabalha e as suas vidas.

O depoimento a seguir veio de um jovem que começa a trabalhar muito cedo com o seu tio, e pensa em crescer profissionalmente naquilo que faz. Pelas suas falas, os pais não acreditavam que ele fosse capaz de estudar. Em seu relato ele diz o seguinte:

(...) Eu parei porque não gostava da escola que estudava, até hoje quando passo por lá ficou meio assim "urgh", como estudei neste lugar? Sei lá, gostava dos colegas e até de alguns professores, mas achava que aquilo tudo não me servia de nada, sabe, parecia que eles falavam outra língua! (Deucalião, 21 anos, solteiro) 
O olhar desse jovem estudante para o espaço escolar que frequêntou foi de um local hostil, diferente do que ele desejava. Ao procurar o PJU, esse aluno disse que sua intenção era de profissionalização, mas também entendia que o certificado do ensino fundamental poderia Ihe servir para acessar outras instâncias, como melhorar de trabalho, entrar no ensino médio, e de tirar sua carteira de motorista.

Bom, vou fazer o PJU nesse colégio mesmo, o pessoal já tá combinando, vão ficar tudo aqui. Só que antes quero tirar minha carteira de motorista, quero ir também para Ponta Grossa no Paraná, fazer um curso de vigilante, agora com o diploma já posso fazer. Vigilante ganha mais e trabalha em uma empresa, tem carteira assinada, quero sair da obra. (Jasão, 19 anos, solteiro)

Atentamente, lendo esse depoimento, percebo que a necessidade de estar com um grupo que já se conhece fortaleceu sua entrada no PJU.

Outra jovem, ao ser entrevistada, demonstra uma certa descontextualização da escola com sua vida; no caso dela, uma vida na roça, cansativa, em que, pelas suas falas, havia um grande esforço para estudar, mas o tratamento que recebia naquele espaço a desestimulava.

(...) os professores me xingavam e me botavam para fora de sala. As professoras me colocavam lá atrás e eu não enxergava direito, e eu queria sentar na frente, mas elas não deixavam, agora veja, já tava cansada, me acordava as 4 horas, em dia de chuva o caminhão passava atolado de gente e eu tinha que caminhar horas e horas de pé, para chega lá e ser xingada, não tinha Cristo que aguentasse, né?! (Afrodite, 30 anos, solteira, 3 filhos)

Essa mesma entrevistada fala que não gostava de trabalhar na roça, queria de fato estudar, sempre gostou de ler e sentia que podia ir adiante nos seus estudos. Ela relata que: "Na real, pensava que pra trabalhar na roça não precisa de estudo! Eu não gostava de trabalhar na roça, mas era obrigada, tinha época boa, na colheita do algodão que vinham muita gente de fora e fazia muitos amigos". 
A aluna do PJU/SC se viu obrigada a deixar de estudar, o seu olhar agora é bem diferente em relação ao que vivenciou.

Se tivesse a cabeça que tenho hoje não parava de estudar agora, hoje em dia que vejo que a vida não é como eu pensava, que a cidade é completamente diferente da roça, se eu tivesse juízo que tenho hoje eu já tava formada, só que não posso voltar atrás no tempo. Agora tenho que seguir em frente, dar um exemplo melhor para meus filhos. Agora com meus 30 anos que tenho que correr atrás de algo melhor, de uma profissão melhor. (Afrodite, 30 anos, solteira, 3 filhos)

A jovem quer ir além do PJU, quer fazer faculdade de direito, esse desejo de que a educação vai abrir portas para o trabalho está no imaginário dos jovens, já que é comum ouvir que se "não estudarmos, não seremos ninguém na vida". O relato da jovem mostra que a sua escolha tem relação com a sua vida social e relação com as pessoas.

(...) acho que porque eu trabalhei com um advogado e gostei do jeito, sabe, o jeito de lidar com as pessoas, tem que ler muito, e eu adoro ler. Então advocacia é isso, você tem que ler, resumir, tem que participar de parte da vida dos outros. Eu não sei é porque gosto muito de conversar e as pessoas gostam de conversar comigo. Uma vez, me disseram para fazer pra psicóloga, eu disse não, eu não quero ser psicóloga... Acho que dá muito problema, é uma carga muito pesada, não quero tanto contato assim com as pessoas. (Afrodite, 30 anos, solteira, 3 filhos)

Outra questão que merece destaque para compreensão dos sujeitos jovens que passaram pelo PJU/SC, é em relação aos motivos que os fizeram voltar a estudar e porque escolheram o ProJovem.

Os jovens não têm condições de estudar, preferem trabalhar já de cedo para ajudar os pais a manter a casa. Nós passamos por dificuldades para ir para a escola por causa do trabalho, pois chegamos cansados. Agora aqui na escola estudo para ser alguém na vida, com dignidade e ter um bom futuro pela frente. Quem sabe arrumo um emprego decente de carteira assinada. (Ares, 25 anos, solteiro) 
Sempre quis voltar a estudar, mas parei quando me casei e tive meus filhos. Já tentei fazer supletivos, mas não gostei, pois as aulas eram apenas uma vez por semana ou pelo sistema de módulos, seguidos de provas, não possuíam explicações nem conteúdos interessantes nas disciplinas. Eu já estava conformada e desanimada, por não poder estudar do jeito que eu gosto todos os dias na escola participando com professores e colegas. (Atenas, 22 anos, casada, 2 filhos)

No meu modo de ver, pelo menos pra mim, foi ótimo tomar essa decisão, pois já havia perdido as esperanças; várias vezes perdi oportunidades boas de emprego porque não tinha qualificação e um diploma embaixo dos braços. Sei que meus 28 anos ainda tenho muito o que aprender, mas como diz o ditado nunca se é tarde quando se temos força de vontade sem falar nas novas amizades que temos, os professores todos muito bem qualificado com bastante conteúdo e dispostos a nos ajudar com empenho e dedicação. (Morfeu, 28 anos, solteiro, 2 filhos)

Já vi pessoas de 25 anos que se acham velhas demais para estudar, mas isso não é verdade, pois nunca é tarde para aprender. (Dionísio, 29 anos, casado, 3 filhos)

Foi aí que apareceu uma moça na porta da minha casa e falou que eu poderia concluir o ensino fundamental em um ano e meio então agarrei essa oportunidade. Passei algumas dificuldades no período mas estou feliz em ter conseguido chegar ao final com a ajuda dos professores e alguns amigos. Então a minha vitória está concluída e agora pretendo terminar o ensino médio para poder me realizar por completo. (Prometeu, 26 anos, solteiro)

Os jovens têm muitas vontades que se entrelaçam com as dificuldades cotidianas; muitos atribuem o seu retorno pela busca de qualificação, informática e elevação da escolaridade, fatores que unem-se ao desejo de conseguir um melhor emprego, "melhorar de vida".

Na EJA o trabalho é uma questão presente. Seja porque os alunos estão tentando manter seus empregos, seja porque estão procurando se qualificar para conseguirem um, seja porque acreditam que só com a educação poderão consegui-lo mais adiante. Mesmo os jovens que nunca 
tiveram uma experiência atribuem grande importância à escola para conseguirem uma profissão. (GONÇALVES, 2012, p. 39)

Torna-se um grande desafio para o desenvolvimento de políticas públicas que tenham um olhar para as várias juventudes, pois esses sujeitos agem no mundo e sob o mundo, reconhecem a busca do saber como uma necessidade, apropriam-se do social e apresentam suas posições, seus interesses que garantem a sua participação social (CHARLOT, 2001).

O depoimento de uma jovem que frequentou as atividades do PJU/SC demonstrou a necessidade de trabalhar; ela diz: "Tive que sair da aula quando estava na quinta série para poder trabalhar e ajudar em casa, agora faço ProJovem, mas não sei se vou conseguir terminar. Preciso trabalhar, tenho uma filha de 2 anos" (Graças, 27 anos, solteira, 2 filhos).

Para esses estudantes, embora as dificuldades em conciliar emprego, família, lazer e estudos seja um fator agravante para a continuidade na EJA, as estratégias realizadas para que se mantenham no curso garantem sua conclusão. Essas estratégias são construídas e desenvolvidas por meio das relações tecidas entre sujeitos (estudantes e professores) que fazem do espaço destinado à escolarização um espaço reconhecidamente de aprendizagem. O espaço praticado da EJA se concretiza quando esses sujeitos se percebem como sujeitos de direitos, valorizados em suas trajetórias de vida, sonhos e projetos frente à escolarização. (FURINI, DURAND e SANTOS, 2011, p. 201)

Para os sujeitos em situação de vulnerabilidade econômica e social, "viver significa ter o que comer, ter um salário" (ARROYO, 2005, p. 9). No entanto, os estudantes da EJA estão sempre em busca de um desenvolvimento pleno, são pessoas batalhadoras, em momentos inseguras, mas otimistas, têm fragilidades, todavia são muito fortes, se desiludem com a vida, mas querem o melhor para si. "Neste sentido é que os sujeitos da Educação de Jovens e Adultos se constroem no querer e no desejo da conquista de novos conhecimentos, indo de encontro, muitas vezes, a uma sociedade que subtrai e exclui 
estes estudantes da oportunidade da vivência" (FURINI, DURAND E SANTOS, 2011, p. 166).

Em Santa Catarina, os professores do PJU se envolviam com as comunidades em que os jovens moravam, reconheciam seus espaços para assim, poder incentivá-los. Além disso, havia um tempo destinado ao professor para fazer o que era chamado de "resgate" dos jovens, que consistia na ida do professor na residência do aluno que estava ausente das aulas por mais de três dias sem justificativa. Esta ação causou surpresa nos alunos, que relatavam admirados: "Não acreditei que o professor foi lá em casa, nunca tinha acontecido isso", "Me senti muito importante", "Se ele não tivesse ido me buscar, eu não tinha voltado”, “ Muitas vezes só vou para jantar, e quando tô saindo porta afora, lá vem um professor atrás de mim, aí eu volto, né?”, “Com uns quatro meses de aulas, eu quase desisti, mas os professores foram lá em casa me chamar, me senti importante, e aí voltei" (Fonte: arquivo pessoal, falas informais de vários alunos e alunas do PJU/SC). $\mathrm{O}$ acolhimento é motor condutor na Educação de Jovens e Adultos; os elos afetivos despertam o interesse e a motivação dos educandos, levando-os a se sentirem seguros e parte do grupo.

Tal ideia se justifica pelo fato de ouvir relatos de alguns alunos e alunas, que diziam que permaneciam no programa pela forma com que o professor conduzia suas atividades. Muitos desejavam desistir, mas não o faziam porque gostavam muito dos professores, tinham neles uma pessoa central, e por isso se esforçavam para conciliar casa, trabalho, família e ProJovem. Na Educação de Jovens e Adultos, o professor assume um papel de vital importância, é ele que pode fazer com que o educando vislumbre outros olhares, sinta-se acolhido, pertencente àquele espaço.

Os alunos, como todo ser humano, são indivíduos singulares e, como todo ser humano, membros de uma sociedade. Todo ser humano é indissociavelmente social e singular, e não há nenhum sentido em se perguntar qual a parte do social e a do singular. Sou 100\% social (senão, não seria um ser humano) e 100\% singular (porque não há dois seres humanos semelhantes) e o total ainda é $100 \%$ e não $200 \%$. Em termos mais científicos as relações entre social e singular são multiplicativas e 
não aditivas. O que é preciso compreender é a forma social de ser singular e a forma singular de ser social. (CHARLOT, 2001, p. 25)

Desse modo, a relação professor/aluno fortaleceu as identidades sociais e profissionais, indicou formas de trabalhar com os jovens, compreendendo a juventude não apenas como uma fase da vida, mas de maneira plural e diversificada.

\section{Considerações finais}

Considerando que as temáticas que envolvem as diversas juventudes têm uma discussão recente, tornou-se importante verificar como há pesquisadores preocupados com o assunto, e como as políticas públicas para a juventude vêm buscando integrar e assegurar os direitos dos jovens nos mais variados programas. Mesmo que ainda sem muitos instrumentos que reconheçam os jovens como protagonistas de sua história, há uma forte preocupação em reconhecê-los como sujeitos fazedores de seu espaço, social e cultural.

A constituição de políticas destinadas a atenderem a juventude se traduz como um esforço no sentido de identificar pontos de estrangulamento que prejudicam o andamento e crescimento do país (de acordo com os debates nacionais). A “juventude, bem como as questões usualmente associadas à condição juvenil vem orientando, com peso ora mais decisivo, ora menos, as ações direcionadas aos jovens" (AQUINO, 2009, p. 35). Geralmente, tais ações se configuram em políticas públicas pontuais que concentram suas ações nas áreas de educação e trabalho, e acabam por não se estruturarem de fato, como "políticas de juventude, mas como estratégias de atuação da sociedade para orientar a formação de jovens e minimizar seu envolvimento em situações de risco" (AQUINO, 2009, p. 35).

Não obstante a relevância da temática juvenil contribui para o reconhecimento dos jovens como sujeitos de direito, pertencentes a um grupo social singular. O perfil dos jovens do PJU apresentou aspectos que devem ser considerados nas políticas públicas de elevação de escolaridade. Questões referentes a gênero, raça/etnia, mercado de 
trabalho, dentre outras, demonstram que a condição juvenil não é a mesma para todas as classes sociais. Todavia, tornou-se evidente que, os jovens que fizeram parte do ProJovem Urbano, seja em âmbito nacional, ou na esfera estadual, se assemelharam em algumas características.

São jovens que sofrem privações, não apenas pela situação de pobreza, mas por estarem em situação de vulnerabilidade social.

Ao comparar as diferenças existentes entre homem e mulher, percebeu-se, ainda mais, as desigualdades em relação ao gênero, e ao observar, a cor/etnia dos jovens que fizeram parte do PJU, evidenciou-se que os sujeitos que se encontram em maior vulnerabilidade social, se declaram como negros ou pardos, e as relações de desigualdade, sejam referentes a gênero ou a cor/etnia, carregam marcas históricas e culturais, decorrentes de uma sociedade patriarcal, capitalista e escravagista.

Outro fator que se mostrou relevante para o entendimento da juventude do PJU, tem relação com a necessidade de trabalhar. Não são apenas estudantes, são trabalhadores, e a busca pelo sustento diário, sobrepõe o desejo de estudar.

Foi perceptível reconhecer na trajetória dos alunos entrevistados as dificuldades encontradas durante seu percurso na escola esta é uma realidade comum entre os jovens da EJA, e a busca por uma vida melhor é o que os faz voltar a estudar. O fortalecimento da relação professor-aluno e o acolhimento dos jovens por parte dos docentes dinamiza uma melhor práxis pedagógica. Quando o professor conhece as necessidades dos educandos, ele pode interagir melhor no processo ensino-aprendizagem.

No entanto, também se tornou perceptível que os sujeitos da Educação de Jovens e Adultos que não tiveram a oportunidade de concluir seus estudos na idade regular, em geral, foram excluídos do sistema formal de ensino, por não se adaptarem às normas exigidas. Na verdade, poder-se-ia dizer que a maioria deles nunca saiu totalmente da escola, mas viveu momentos de fragilidades, que os fez adiar a educação escolar naquele momento. A rigidez adotada nos espaços escolares e, por alguns educadores, afastou esses sujeitos. 
O histórico da educação para jovens e adultos passou por vários conflitos, e algumas pessoas até hoje não compreendem o que ocorre com estes sujeitos que não conseguem se adaptar a estes modelos prontos de escolas. Os sujeitos das EJAs tornamse pessoas invisíveis, identificadas por suas ausências e carências.

Não obstante, esse breve artigo não tem a pretensão de esgotar toda a temática das juventudes, mas de levantar questões referentes às peculiaridades das identidades juvenis, contribuindo, assim, para mais e melhores políticas públicas.

\section{Referências}

ABRAMOVAY, Miriam; ESTEVES, Luiz Carlos Gil. Juventude, Juventudes: pelos outros e por elas mesmas. In: ABRAMOVAY, Miriam; ANDRADE, Eliane Ribeiro e ESTEVES, Luiz Carlos Gil (Orgs). Juventudes: outros olhares sobre a diversidade. Brasília: Ministério da Educação, Secretaria de Educação Continuada, Alfabetização e Diversidade; Unesco, 2008.

ARROYO, Miguel González. Educação de jovens - adultos: um campo de direitos e de responsabilidade pública. In: SOARES, Leôncio (Org.). Diálogos da educação de jovens e adultos. São Paulo: Autêntica, 2005.

AQUINO, Luseni. A juventude como foco das políticas públicas. In: AQUINO, Luseni; ANDRADE, Carla; CASTRO, Jorge Abrahão (Orgs.). Juventude e políticas sociais no Brasil. Brasília: IPEA, 2009.

BRASIL, Coordenação Nacional do ProJovem Urbano. Projeto pedagógico integrado (PPI) do ProJovem urbano. Brasília: Secretaria Nacional de Juventude, 2008.

CARRANO, Paulo César. Educação de jovens e adultos e juventude: o desafio de compreender os sentidos da presença dos jovens na escola da "segunda chance". Reveja - Revista de Educação de Jovens e Adultos, v. 1, n. 0, ago. 2007.

CARRANO, Paulo César; SPOSITO, Marília Pontes. Juventude e Políticas Públicas no Brasil. In: Oscar Dávila León (Editor). Políticas públicas de juventude na América Latina: políticas nacionales.Viñadel Mar: Ediciones CIDPA, 2003. 
CHARLOT, Bernard (Org.). Os jovens e o saber: perspectivas mundiais. Porto Alegre: Artes Médicas, 2001.

FURINI, Dóris Regina Marroni; DURAND, Olga Celestina da Silva.; SANTOS, Pollyana. Sujeitos da Educação de Jovens e Adultos, espaços e múltiplos saberes. In: LAFFIN, Maria Hermínia Lage Fernandes (Org.). Educação de jovens e adultos e educação na diversidade. Florianópolis: Universidade Federal de Santa Catarina, 2011.

GONÇALVES, Rita de Cassia. Educação de jovens e adultos e o mundo do trabalho. In: LAFFIN, Maria Hermínia Lage Fernandes (Org.). Educação de jovens e adultos, diversidade e o mundo do trabalho. ljuí: Ed. Unijuí, 2012. 